\title{
David Sackett on the move; Paul Glasziou takes over
}

This issue of Goidence-Based Medicine marks a change of co-editor. David Sacket, one of the founding editors of Evidenc-Based Medicine, has resigned this post to begin his next career. Paul Glasziou las aken Sacketrs place as co-editor.

Dave Sackett's contributions to health cove over the years are most notable in 3 arenas: research methods for applied testing of innovations; use of these methods to evaluate the scientific validity and clinical merit of numerous health care interventions; and education of cliricians in understanding and applying the resul ts of current best evidence from tesearch in clinical practice. These contributions have greatly enhanced the rigor and power of researcin methods in dinical epidemiology, leading to its evolution as a foundation for evidencebased health care.
Sackett's work with evidence-based journals, beginning with ACP foumal Chb in 1990, was nourished by these deep roots. The journals have become the working tools of practitioners determined to provide evidence-based care without always having the time, or even the skills, to try to do so by reading and interpreting research reported in traditional medical journals.

Sacket clams that his accomplishments are guided by 3 "principles oflife": loyalty to people always and institutions never; service to the young; and remem. bering that you can become as good as you pretend to be. The editors and staff of Evidence-BasedMedicine have benefited enormously from David Sackett's vigorous pursuit of these ideals and wish to acknowledge their huge debt to him as he goes on to the next stage of his career.
Dave has moved from Oxford back to Canada, indeed to its rural hinterland. He indicates that he will be hooked up by geostationary satellite (or whatever is available) and Internet technology to conduct teaching sessions in clinical epidemiology and Internet-run studies of the value of clinical observations for the diagnosis, prognosis, and management of various disorders, work that he has been gearing up for recently. This is the next phase of his remarkable career, which has inchuded being the founding chair of the Department of Clinical Epidemiology and Biostatistics at McMaster University; chief of medicine at Chedoke-McMaster Hospitals in Hamilton, Ontario: sor and founder of the first $C$ Evidence-Based Medicine journal editor; and, alw educator; and mentor.

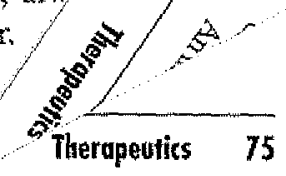


The next issue of Evidence-Based Medicine marks a new era for the journal in another way, too. Although we have attempted to serve a broad and general clinical andience with content that includes internal medicine, obstettics, gynaecology, paediatrics, psychiatry, surgery, and family medicine-general practice, our primary target audience has always been primary care physicians. Paul Glasziou is a practicing general practioner in Brisbane, Australia, where he keenly pursues the best evidence for his patients. He is also an associate professor in the Department of Social and Preventive Medicine at the University of Queensland and holds a PhD in decision analysis. His research and teaching interests are in imptoving medical decision making, cinical trials, systematic reviews, and evidence-based medicine. He has applied his skills to such topics as breast and colorectal cancer screening, acute otitis media, cholesterol lowering, and anticoagulation for atrial fibrillation. Thus, Paul Glasziou is a member of the clinical discipline of prime interest for Evidence-Based Medicine and has the training and experience in research and evidence based decision making that will provide our readers with accurate and practical summaries of current best evidence for primary care.

On behalf of all the staff and collaborators of Evidence-Based Medicine, I bid a fond farewell to David Sackett and extend a hearty welcome to Paul Glasziou.

Brian Harnes, $M D, P h D$ Co-editor
Best Evidence 3 is available now! We are delighted to announce the arrival of Best Evidence 3 . This CD includes all contents from $A C P$ Fotwnal Club and Evidence-Based Medicine up to the end of 1998 , with ipdating of the content from 1993 , in a searchable database. To order, contact the American College of Physicians-American Society of Internal Medicine at 800-523-1546 (www.acponline.org/catalog/cbi/ best_evidence.htm) or the BMJ Publishing Group at 44-171-3836270 (www.bmjpg.com/datal ebm.htm).

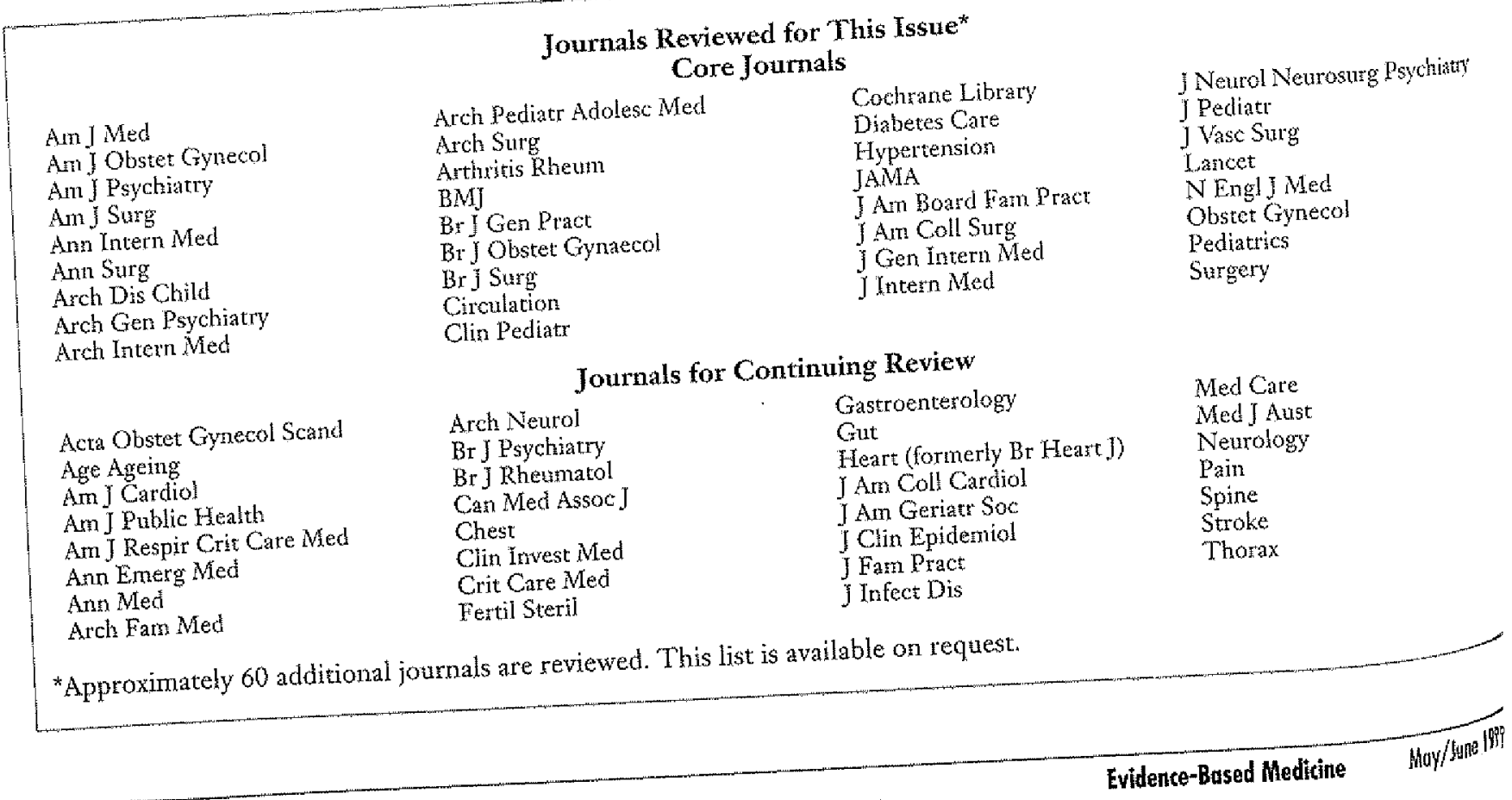

